\title{
Re-enfranchising Mathematically-alienated Students: Teacher and Tutor Perceptions of the Getting Ready in Numeracy (G.R.I.N.) Program
}

\author{
Penelope Kalogeropoulos ${ }^{1 *}$, James A. Russo ${ }^{1}$, Peter Sullivan ${ }^{1}$, Michele Klooger ${ }^{1}$, Sue Gunningham ${ }^{1}$ \\ ${ }^{1}$ Monash University, AUSTRALIA \\ *CORRESPONDENCE: \ penelope.kalogeropoulos@monash.edu
}

\begin{abstract}
This paper outlines a tutoring initiative intended to re-engage students who have become alienated from mathematics class at school. The initiative is focused on priming students for their subsequent mathematics lessons, and is referred to as "Getting Ready in Numeracy" (G.R.I.N.). Following a discussion outlining the principles of G.R.I.N., data from interviews with G.R.I.N. tutors and classroom teachers are presented. Findings suggest that participating in G.R.I.N. enhanced student engagement in mathematics and helped foster a growth mindset. Analysis of interviews also revealed some of the challenges associated with the initiative, in particular, issues relating to communication and coordination, such as: understanding the purpose of G.R.I.N., timetabling, planning and having sufficient students in the target group. In addition, in some instances, tensions between the professional and pedagogical expertise of the G.R.I.N. tutor and classroom teacher required navigation. Recommendations for mitigating these challenges and tensions are put forward, all of which are reliant on strong leadership and support for the program at the school level.
\end{abstract}

Keywords: intervention programs, growth mindset, student engagement, cognitive-load theory, social-cognitive theory

\section{INTRODUCTION}

By the time they reach the middle primary years, wide differences in mathematics achievement between students are apparent (Thomson, Wernert, O’Grady, \& Rodrigues, 2016). The differences present curriculum, pedagogical and assessment challenges for teachers (Sullivan, Mousley, \& Zevenbergen, 2006). Some schools and systems address the challenges by grouping students by their achievement even though, as described by Hattie (2009) in a comprehensive review of over 300 studies, this creates "profound negative equity effects" (p. 90). Yet even when students are grouped by achievement, teachers still confront wide differences in the knowledge and dispositions of students. It even seems that some students actively resist engaging in learning opportunities that mathematics classes offer. This resistance may be partly attributable to such students having missed out on learning the necessary language and concepts in earlier years and partly attributable to them coming to believe that they cannot learn mathematics. It appears that some students have missed out on learning so many concepts and have developed such entrenched negative attitudes that it is very difficult for classroom teachers to address this resistance, at the same time as coping with the complexity of everything else happening in their classrooms.

Article History: Received 15 April $2019 \bullet$ Revised 31 May $2019 \bullet$ Accepted 31 May 2019

(C) 2020 by the authors; licensee Modestum Ltd., UK. Open Access terms of the Creative Commons Attribution 4.0 International License (http://creativecommons.org/licenses/by/4.0/) apply. The license permits unrestricted use, distribution, and reproduction in any medium, on the condition that users give exact credit to the original author(s) and the source, provide a link to the Creative Commons license, and indicate if they made any changes. 
The current paper describes a program for re-engaging disengaged students that is different from common "catch them up" approaches. One such program, QuickSmart (Graham, Pegg, Bellert, \& Thomas, 2007), involves active teaching both in classrooms and in withdrawal settings, the intention of which is to develop fluency and confidence with recall of small number calculations. The intervention described here, titled Getting Ready in Numeracy (G.R.I.N.), aims to prepare students for mathematics classroom experiences they will have subsequent to the tutoring.

There are three separate but critical components that are addressed in the professional learning associated with the G.R.I.N. program. First, teachers plan sequences of lessons with specific goals that address the diversity of prior mathematical knowledge of the students. Second, the teacher communicates the goals of the upcoming lessons to the tutor. Third, the tutor plans intervention sessions which include three elements aimed at getting students ready for subsequent learning: targeted fluency practice; language development; and developing familiarity with key pre-requisite concepts. For example, if the teacher was planning an introduction to the theorem of Pythagoras, the tutor might plan to revisit squares and square roots, might explore what the tutored students know about the hypotenuse, and might revise equations with unknowns and properties of right angled triangles. There is a double advantage in that students not only learn prerequisite concepts in the tutoring session but also in the mathematics class.

Building on an evaluation of the 2010 G.R.I.N. pilot program, which included consideration of student performance data (see Sullivan \& Gunningham, 2011), the focus of the current study is on examining teacher and tutor perceptions of the program. Specifically, it involves in-depth interviews with four educators (two teachers and two tutors) whose schools were recently involved in G.R.I.N. to gauge their perspectives on the student experience of G.R.I.N., as well as some of the challenges associated with implementing the program.

\section{G.R.I.N. Program Overview}

The G.R.I.N. intervention program is intended to provide support for primary and secondary students experiencing difficulty in mathematics. G.R.I.N. sessions are conducted in addition of, and prior to, mathematics lessons. The program is delivered by appointed G.R.I.N tutors who have been qualified in the G.R.I.N. model of intervention. The tutor may be a classroom teacher or a specialist G.R.I.N. tutor. A qualified tutor conducts the G.R.I.N. sessions with a small groups of students. The optimum group size for an intervention group is three students. This allows students to work in pairs or triads to complete activities and also provides opportunity for some one-on-one time with the tutor.

The key idea is for the G.R.I.N. tutor to prepare the intervention students for their subsequent classroom mathematics lesson. Specifically, the tutor needs to identify the key vocabulary that the student will confront during the lesson, the concepts that will be addressed, the materials and tools that will be used and the types of activities that will be posed. Tutors should seek students' current understandings of the mathematics topic and clarify any misconceptions. G.R.I.N. sessions follow a consistent lesson structure that helps to focus on the key ideas in an efficient manner. Using the same lesson structure for all sessions establishes a routine that settles students quickly, thereby maximizing the time available.

Students are generally required to attend (at least) three G.R.I.N. sessions per week however this is dependent on individual student needs and/or timetable constraints. The tutor should aim to withdraw students from a range of different subject areas during the week to help minimize the disruption to students' learning in other areas. The duration of a G.R.I.N. session is between 15 and 25 minutes and is conducted prior to the mathematics lesson. Generally, a G.R.I.N. group runs for six month increments.

Selecting students with the greatest potential to benefit from the program is an important consideration. The G.R.I.N program targets students beyond the early years of schooling (generally Years 3 and above), ideally those who have been identified as being in the second bottom quintile (i.e., between the 20 and 40 percentile) for mathematics. The G.R.I.N. program may particularly benefit those students whose low engagement in the classroom is linked to a lack of understanding and confusion about the key ideas of the lesson. Assessment tasks such as the Mathematics Assessment Interview (MAI) can help identify students for inclusion in the program. Post data should also be collected to help monitor individual G.R.I.N student progress and to help the teachers and tutor decide which G.R.I.N students should be continued on the program for a further six months, as well as any additional supports that may be needed for those students being exited from the program.

The G.R.I.N. program relies heavily on the development of strong and timely communication between the G.R.I.N. tutor and the classroom teacher. The closer the link between the intervention session and the 
subsequent mathematics lesson, the more impact the program is likely to have on student outcomes. The communication between the classroom teacher and the tutor provides a two-way flow of information that benefits both the intervention program and the classroom experience. During mathematics lessons, the classroom teacher supports the work of the tutor by calling upon the G.R.I.N. students to provide explanations and suggestions that recognise their prior learning and to further build their confidence. The classroom teacher is able to provide feedback to the tutor about any changes in the student's participation in class as a result of the intervention experience.

School leadership (e.g. the school principal) needs to work closely with the G.R.I.N. tutor and classroom mathematics teacher to organize for the G.R.I.N. session to be timetabled before each mathematics lesson. A G.R.I.N. tutor must be appointed. Planning time for the tutor and classroom teacher must also be organized and ideally timetabled. A suitable meeting room must be made available for the G.R.I.N. sessions and it should also be resourced with mathematical resources (e.g. calculators, rulers, etc.)

\section{Program Rationale and Theoretical Perspective}

G.R.I.N. is informed by three complementary strands of research. The first strand is based on views of cognition, and, in particular, cognitive-load theory. The second strand is associated with student beliefs about themselves as learners and its interaction with student affect. The third strand relates to the social context of the classroom, and how such contexts create opportunities for learning through discourse and peer-to-peer interactions. Taken together, this research base suggests three principles of effective intervention design in mathematics education:

Principle 1 (Cognitive-load rationale): Students behind in mathematics will benefit from exploring the relevant concepts and procedures before the whole-class lesson, particularly if the content is sufficiently broken down for students.

Principle 2 (Cognitive-affective rationale): Students with low self-concept as mathematicians, who become familiar with concepts and procedures in advance of the whole-class lesson, are more likely to participate fully in the lesson, and develop a mastery-orientation towards mathematics.

Principle 3 (Social-cognitive rationale): Students benefit by learning mathematics through discussion and exploration of concepts and procedures with peers.

\section{The cognitive-load rationale: Principle 1}

Part of the rationale for the G.R.I.N. intervention is derived from cognitive load theory. As described by Bransford, Brown, and Cocking (1999), the theory suggests that information is processed in working memory and then stored in long term memory. Ideally information stored in long term memory is efficiently chunked so that it can be readily retrieved. The initial processing of information and preparation for this chunking happens in working memory, which is of limited capacity.

According to Sweller (2010), there are three types of cognitive load. Intrinsic cognitive load is dependent on the inherent complexity of the material to be learnt, and the relationship of this material to the expertise of the learner. Extraneous cognitive load can be viewed as wasted cognitive load created by less than ideal instructional design. Germane cognitive load is the cognitive load dedicated to actually learning the material. The implication is that the goal of instructional design should be to minimize extraneous cognitive load, maximize germane cognitive load, and optimize intrinsic cognitive load (Huang, 2018).

In classrooms, students attend to stimuli around them and then select information for processing. Students who are not familiar with pre-requisite concepts and language have difficulty in selecting appropriately and so the instruction, the task, the language, and even what other students are saying and doing, overloads their working memory. Technically, in cognitive-load parlance, the intrinsic cognitive load of the material being presented is too high (Sweller, 2010).

One particular approach to supporting learners confronted by such material that has been suggested within the cognitive load literature is the progressive method (Pollock, Chandler, \& Sweller, 2002). The progressive method involves not presenting all the information to be learnt in the first stage, but instead isolating certain aspects of the learning material, and presenting these isolated aspects serially to the learner. Through dividing up the material in this manner, the interactivity amongst the elements of the task or activity is reduced. In the second stage, all material is then presented to the learner in its entirety. Pollock et al. demonstrated that the progressive method, that is, this approach of presenting elements in isolation before 
presenting all the material, resulted in higher levels of understanding than an alternative learning condition involving multiple presentations of the full material to be learnt. Van Merrienboar and Sweller (2005) conclude that "in general the progressive method is an appropriate technique to use for novice learners who are confronted with highly complex materials but who lack the rudimentary schemata for dealing with those materials" (p. 157).

These findings appear to have clear implications for teachers and schools who have students who are having difficulty with school mathematics. If students are struggling with the material, and are well behind their peers, simply presenting the material to them on multiple occasions (e.g., attending extra instructional sessions) is unlikely to be particularly effective. Instead, students would appear to benefit from 'front-loading' or 'priming', whereby they are given opportunities to engage with a deconstructed version of the lesson material in advance of attending the lesson. This idea of front-loading or priming students prior to their mathematics lessons is at the heart of the G.R.I.N. intervention.

\section{The cognitive-affective rationale: Principle 2}

The cognitive-affective rationale for the G.R.I.N. approach is that it appears that some students have come to believe that they cannot learn mathematics, which limits their willingness to engage with learning experiences. Martin and Marsh (2006), for example, argue that self-concept is a key determinant of learning outcomes for all students, and that negative self-concept is especially detrimental for low achieving students. Dweck (2000) proposed that finding ways to support low achieving students is as much connected to their orientation to learning as it is to their level of knowledge. Dweck categorised students' orientation to learning in terms of whether they hold either mastery goals or performance goals. Dweck argued that students with mastery goals seek to understand the content, and evaluate their success, by whether they feel they can use and transfer their knowledge. In contrast, students with performance goals are, at best, interested in whether they can perform assigned tasks correctly. Students with performance goals tend to conceptualize their own competence as being relative to peers, rather than adopting what might be characterized as an intrapersonal mastery standard (DiNapoli, 2019).

Dweck connected performance goals to a fixed view of intelligence in which students believe that the intelligence that they have is what they were born with and which cannot be changed. Indeed, Dweck (2008) has also referred to students with performance goals as possessing a fixed mindset. By contrast, students with mastery goals see intelligence as incremental and feel they can change their intelligence or achievement depending on factors over which they have some control. Students with a mastery orientation therefore tend to possess a growth mindset (Dweck, 2008). An additional learning disposition associated with a fixed mindset that is particularly critical for students from middle primary levels upward was described by Elliot (1999) as performance avoidance. This refers to the notion that some students choose not to engage in a task or experience at all rather than trying at the task and failing (see also Desforges \& Cockburn, 1987).

G.R.I.N. attempts to re-orientate students with a negative self-concept as mathematics learners towards a mastery orientation. The underlying assumption is that if the risk of failure is reduced through increased familiarity with the focus content and associated processes, then students who would otherwise be disinclined to participate may join in with others in attempting the tasks set. This initial familiarity will support the belief that, through effort, the student can come to have success with the material presented.

Another element contributing to the cognitive-affective rationale for G.R.I.N. is that of student engagement. Student engagement has an extensive research base (Fredricks, Blumefeld, \& Paris, 2004) and is shown to be a complex and multi-faceted construct. Engagement involves three commonly identified dimensions: affective engagement, behavioural engagement and cognitive engagement (Fielding-Wells \& Makar, 2008; Kong, Wong \& Lam, 2003). It is important that the inter-relatedness of each of the individual dimensions of engagement be considered and not assumed. For example, a student not making eye contact with the teacher in class may seem to suggest behavioural disengagement, whilst their attentive listening may be a non-obvious indicator of cognitive and affective engagement.

Sullivan and McDonough (2007) claim that two sets of factors must align to promote student engagement when learning mathematics. The first set includes students having the requisite prior knowledge. As discussed previously, the G.R.I.N. program addresses this issue explicitly through providing students with opportunities to consolidate prior knowledge before exploring a relevant concept in their mathematics classroom. Other factors from the first set include a curriculum that is relevant to students' lives, interesting classroom tasks and pedagogies, and assessment regimes that match the students' expectations. These factors are potentially implicitly addressed within the G.R.I.N. program through mechanisms such as, for example, the mathematics 
teacher meeting regularly with the G.R.I.N tutor to plan the G.R.I.N. sessions and the subsequent mathematics lessons. The second set of factors proposed by Sullivan and McDonough (2007) reflect the individual valuing aspect of engagement, including: the students' goals for learning, their willingness to persist, and the extent to which they see participation in schooling as creating opportunities. This second set of factors highlighted by Sullivan and McDonough overlaps with Dweck's $(2000,2008)$ construct of a mastery goal orientation and the notion of a growth mindset. As noted previously, part of the purpose of G.R.I.N. is to cultivate such values through providing struggling students with opportunities to be successful, reducing the risk of failure, and supporting them to develop greater content mastery.

\section{The social-cognitive rationale: Principle 3}

One question that is beginning to receive some recent attention in the intervention literature is; what is the optimal size for an intervention group? (e.g., Clarke et al., 2017; Vaughn, Thompson, Kouzekanani, \& Dickson, 2003). Within the reading intervention literature, Vaughn et al. (2003) found that a ratio of one educator to three students $(1: 3)$ had a significant impact on student reading performance that was indistinguishable from the same intervention that employed a 1:1 ratio. By contrast, student reading performance was lower for those participants who experienced the intervention in a larger group setting (1:10). Interestingly, however, differences in performance as a product of group size was non-significant in a followup study comparing two larger intervention groups (1:5 vs 1:15) (Vaughan et al., 2010). These findings are consistent with a meta-analysis undertaken by Wanzek and Vaughan (2007) that suggested that, within the reading instruction literature, participating in a small group or a one-to-one intervention is preferable to interventions involving larger groups. Although the authors note that methodological issues prevented them precisely quantifying this effect, they inferred this finding in part from the observation that the three studies with the largest group sizes (e.g., average of 8 students per group; Foorman et al., 1997) reported the smallest effects on reading performance.

Evidence for the notion that small group intervention is as effective as 1:1 interventions is also emerging within the mathematics education field. Although there have been notably fewer studies directly examining this issue to date, Clarke et al. (2017) undertook a 50-lesson intervention with kindergarten students identified as at-risk. The study involved 60 classes of kindergarteners, and 592 eligible students altogether. Students participating in the intervention were randomly assigned to either a group of two or a group of five. Results indicated that the intervention significantly impacted student performance, however, that there was no differential impact according to group size.

Taken together, these results suggest that small group interventions (e.g., three to five students) are likely to be as effective for improving student learning as 1 to 1 interventions, and perhaps more effective than interventions involving larger groups. Given this research-base, we recommend to schools participating in GRIN that the intervention sessions be structured in groups of approximately four (i.e., three students and one educator).

The question arises as to why it is the case that small group interventions appear equally effective as individualized interventions, given that the intensity of an intervention can be assumed to decline for every additional individual that is added to the group.. One explanation put forward by Clarke et al. (2017) is the presence of a threshold effect; suggesting that practicing desired behaviors beyond a certain point is largely redundant. However, an alternative explanation relates to the observation that students learn mathematics through opportunities to construct their understanding in a social context, such as through peer-to-peer interactions (Kieran, 2001; Pijls, Dekker, \& Van Hout-Wolters, 2007; Zakaria, Chin, \& Daud, 2010).

Although we do not want to discount the role of the educator acting as discussion facilitator, we suggest that there at least four advantages to small group discussion over a teacher-student dyad. First, there is some evidence that solution strategies are more salient when presented by fellow students than by the teacher (e.g., Russo \& Hopkins, 2017). Secondly, a discussion involving multiple students is more likely to reveal student misconceptions, and provide a context in which these misconceptions can be explored and challenged robustly. Thirdly, it might be argued that communicating within a dyad is more likely to permit tacit and unarticulated communication, compared with a context involving more than two individuals, where there is necessarily more emphasis on appropriately verbalizing ideas and communicating more explicitly. There is some evidence to support this proposition. For example, Yoon, Thye, and Lawler (2013) found that communication within triads on a set task tended to be more formalized and less emotive than communication within dyads on the equivalent task. The emphasis on developing and using appropriate mathematical language is one of the specific objectives of the G.R.I.N. program, and is linked to the idea that a lack of comprehension of 
mathematical terms and symbols is often a significant barrier to students behind in mathematics engaging in their mathematics classes. Consequently, being involved in a learning context that requires more formal, articulated communication may be advantageous for students. Finally, there is evidence that collaborative learning contexts support the development of metacognitive mathematic thinking processes (Alzahrani, 2017).

An additional reason for suggesting that G.R.I.N. groups be structured as groups of four (i.e., three students and the tutor) rather than groups of three (i.e., two students and the tutor) is due to the fact that G.R.I.N. students tend to have relatively high rates of absenteeism (which, incidentally, is a correlate of low mathematics achievement; Gottfried, 2019). Including three students in a group increases the probability that at least two students will be present in any given G.R.I.N. session. It is also worth noting that there is some empirical support within the G.R.I.N. program for the contention that groups of three students is preferable to other group sizes (Sullivan \& Gunningham, 2011).

One final rationale for G.R.I.N. warrants brief mention; that is, the social-affective rationale. In particular, the reasoning for having multiple students in a G.R.I.N. group goes beyond social-cognitive considerations. Including more than one student in a group helps to normalize participation in G.R.I.N., and provides some peer support for G.R.I.N. students back in the classroom (given that a G.R.I.N. group is taken from a single mathematics class). In addition, the relationship with the G.R.I.N. tutor has the potential to shape student attitudes towards mathematics, particularly when one considers that educator affective support appears to be more important than parental support for fostering more positive student attitudes towards mathematics (Davadas \& Lay, 2018).

\section{Previous Evaluations of the G.R.I.N. Program}

Previous research has found support for the efficacy of the G.R.I.N. program in terms of its impact on student academic outcomes, particularly for secondary students. Specifically, a 2010 trial of G.R.I.N. with Year 3 students from four primary schools, and Year 8 students from two secondary schools, was undertaken (see Sullivan \& Gunningham, 2011). On Demand testing data was utilized to examine growth in student performance between the beginning of Term 1 and towards the end of Term 3. It was found that the 57 Year 3 students participating in G.R.I.N. across the four schools achieved similar growth to the 174 Year 3 students not participating in G.R.I.N. on average (9.2 months growth vs 9,9 months growth), indicating that participation in the G.R.I.N. program had at least managed to prevent these students from falling further behind their peers. Results were even more promising for Year 8 students. Specifically, the 45 Year 8 students who participated in G.R.I.N. achieved more substantial growth than the 234 non-tutored students (11.1 months growth vs 2.2 months growth). The implication is that a typical G.R.I.N. student in Year 8 who began the year six months behind their peers would have 'caught up', and perhaps even surpassed, the typical achieving student in their cohort. The dramatic positive impact of the program for this group is one of the reasons why subsequent iterations of G.R.I.N. have primarily targeted students in the middle years of schooling (e.g., Years 5 to Year 8), and the upper secondary years, rather than the early years of primary school.

In addition to reporting student outcome data, this pilot study involved brief interviews with teachers, tutors, and students with the purpose of examining the experience of program participants, as well as some of the challenges of implementing the program (Sullivan \& Gunningham, 2011). In addition to student learning gains, interviews with all participants suggested that student confidence in mathematics was positively impacted on through participation in G.R.I.N.. Some teachers also identified positive spillover effects on their classroom teaching, suggesting that all students benefited from some students participating in the program, in part because G.R.I.N. students occupied less of the classroom teachers time and attention than would otherwise been the case. Promisingly, there did not seem to be any stigma around students participating in the program.

Analysis of these interviews also identified some important considerations and challenges associated with the pilot program, several of which resulted in concrete recommendations about how schools should implement G.R.I.N. in the future. First, as discussed earlier, a group size of three students was revealed as optimal, as it provided sufficient balance between opportunities for students to interact directly with the tutor, and peer support. Secondly, in an instance of a student being absent, some schools initially replaced the G.R.I.N. students with other students who might potentially benefit from participation. However, this practice was discontinued after it was consistently found to disrupt the dynamics and continuity of the G.R.I.N. groups. Thirdly, it was suggested that the students not be withdrawn from the same lesson repeatedly, as this would undermine their learning in another subject. Fourthly, tutors benefited significantly from opportunities to 
Table 1. Constant Comparative Method (Adapted from Glaser, 1965)

\begin{tabular}{ll}
\hline Step & Description \\
1) Comparing incidents & $\begin{array}{l}\text { After the data are read and reread to identify relevant themes and categories, the } \\
\text { incident (e.g., the section of the relevant transcript) is coded to as many categories of } \\
\text { analysis as possible. The advice is "while coding an incident for a category, compare it } \\
\text { with the previous incidents coded in the same category" (p. 439). }\end{array}$ \\
\hline $\begin{array}{l}\text { 2) Integrating categories and } \\
\text { their properties }\end{array}$ & $\begin{array}{l}\text { Shift in focus from comparing incidents (i.e., Step 1) to developing more general rules } \\
\text { that define a given category arising from analysis of these incidents. This process is } \\
\text { iterative; each incident within that category is compared back to this set of tentative } \\
\text { rules to refine the rules. }\end{array}$ \\
\hline $\begin{array}{l}\text { The original list of categories is reduced, with the goal of developing a smaller set of } \\
\text { categories operating at a higher level of abstraction. The goal is for categories to become } \\
\text { "theoretically saturated", whereby coding an additional incident to that category does not } \\
\text { add to the explanatory power of that category (p. 441). }\end{array}$ \\
\hline Through working back through this process, the analyst is able to explicate their theory.
\end{tabular}

participate in ongoing professional development, particularly in relation to effective questioning skills. One issue that remained largely unresolved for some schools was the challenge of creating adequate time in the schedule for tutors and classroom teachers to meet face-to-face. This in turn impacted on their capacity to coordinate planning.

\section{The Current Study}

The current study will endeavor to build on this initial evaluation of the G.R.I.N. pilot program by collecting qualitative data from G.R.I.N. tutors and classroom teachers from the 2017 and 2018 iterations of the program. This will allow us to examine the benefits of G.R.I.N. to students from the perspective of tutors and teachers, whether the challenges with implementing G.R.I.N. identified at the pilot phase remain, as well as whether additional challenges have emerged or been identified. Specific research questions include:

1) What are the views of G.R.I.N. tutors and classroom teachers as to the student experience of participating in the G.R.I.N. initiative?

2) What are some of the challenges to implementing the G.R.I.N. initiative in a school?

\section{METHOD}

\section{Participants and Procedure}

Participants were two G.R.I.N. tutors and two classroom teachers from four different schools who consented to partake in in-depth semi-structured interviews at the end of the school year around their perceptions of the G.R.I.N. program. Some of the key prompts used during the interviews included probing how the G.R.I.N. program impacted students, teachers, tutors and the teaching of mathematics at the school more generally, as well as some of the challenges, concerns or issues around the implementation of the program.

\section{Analytical Approach}

The Constant Comparative Method (Glaser, 1965) was employed as the preferred analytical approach for making sense of the interview data. The power of this method revolves around its capacity to use data to inform and build theory, and it has links to Grounded Theory approaches (Strauss \& Corbin, 1994). The fourstage process that an analyst needs to work through to employ the Constant Comparative Method is comprehensively outlined in Table $\mathbf{1 .}$

\section{RESULTS}

A summary of the analysis resulting from applying the Constant Comparative Method to the interview data is presented in Figure 1.

The initial coding of the data revealed over one dozen themes, which were eventually distilled into eight categories: Growth mindset, Engagement, Understanding the purpose of G.R.I.N., Timetabling, Planning, Target Group, Implications for how should mathematics be taught and Who is the expert? Consideration was then given to how these categories should be effectively organized (see Table 1, Step 3). Initially, it was envisioned that three meta-categories built around the role of the participants (i.e., tutors, teachers and 

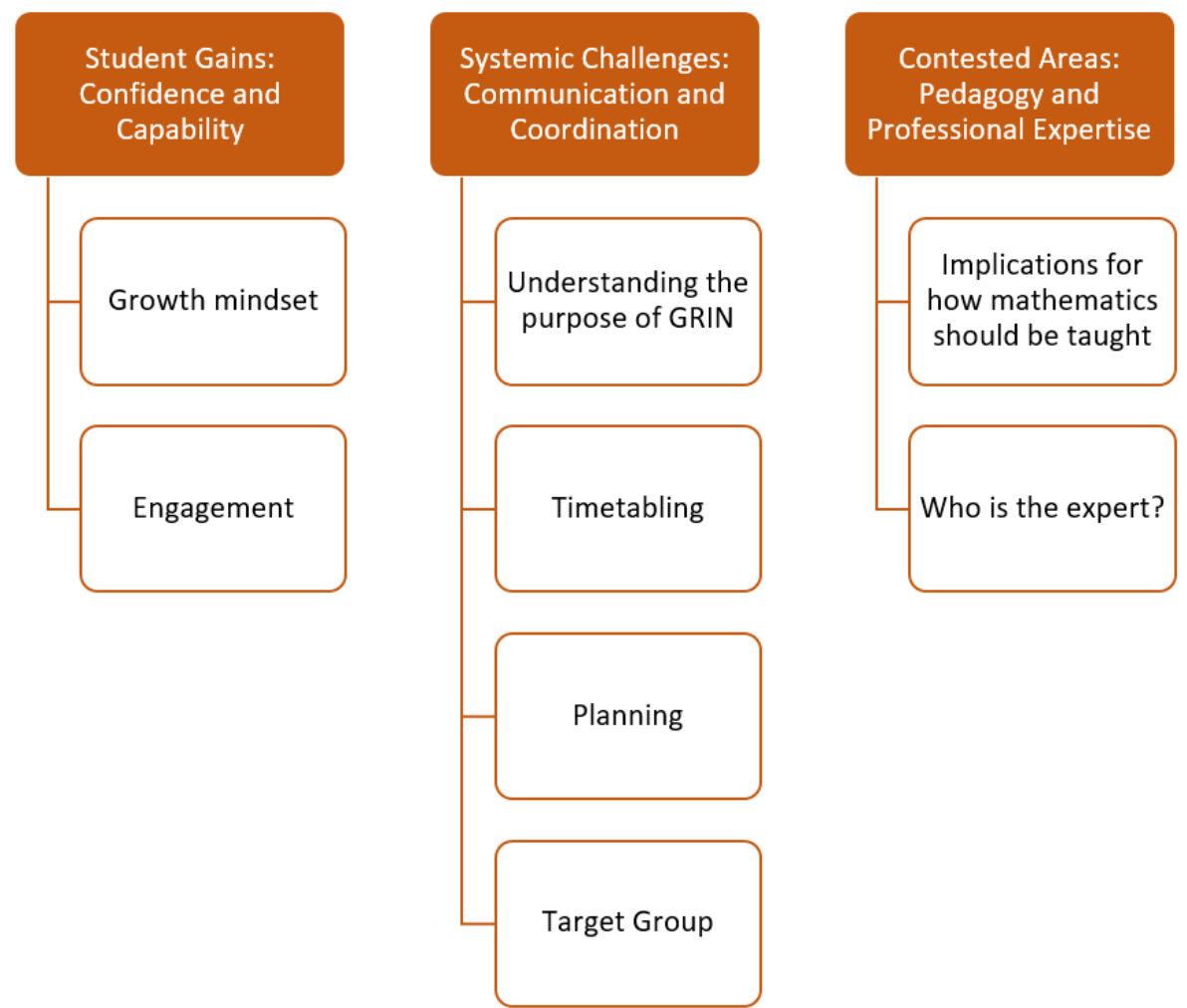

Figure 1. Summary of the analysis arising from the teacher and tutor interviews

students) might be put forward to encompass these eight categories. However the attempt to organize the data in this manner proved inadequate, primarily because some of the themes overlapped participant roles (e.g., Understanding the purpose of G.R.I.N.), whilst other themes actually operated at the intersection of participant roles (e.g., Who is the expert?). Consequently, this approach to developing the meta-categories was abandoned. Instead, a different organizational framework emerged, specifically, the three meta-categories of Student Gains: Confidence and Capability; Systemic Challenges: Communication and Coordination; and Contested Areas: Pedagogy and Professional Expertise. These first two meta-categories were perhaps anticipatable from the previous evaluation into the G.R.I.N. pilot program (Sullivan \& Gunningham, 2011), however the third meta-category (Contested Areas: Pedagogy and Expertise) was perhaps surprising, and testament to the power of undertaking in-depth participant interviews.

The remainder of this section will be organized around these three meta-categories. Extensive quotes from participants will be included when relevant to support the analysis and help illustrate the pertinence of a particular category.

\section{Student Gains: Confidence and Capability}

\section{Growth mindset}

One of the benefits to students of participating in G.R.I.N., at least as perceived by teachers, was the development of a growth mindset in students with regards to their mathematics learning. A growth mindset is characterized by the belief that through sustained effort, one's ability and competency in a given area can be improved. It is generally contrasted with a fixed mindset, which is the belief that one's ability or intelligence is fixed (Dweck, 2008). The construct of a growth mindset overlaps with that of a mastery orientation (Dweck, 2000).

Sarah, a teacher and PLT leader, highlighted the power of students working with G.R.I.N. tutors in order to reframe their experience when confronted with struggle in mathematics class. This reframing involved adopting language that left open the possibility of the student being successful in the future, even if they had not mastered a particular skill or concept in the present: 
We have found that it's made a big difference to the students' attitude to their learning... The tutor that has worked with them has worked on things like growth mindset and has helped these kids who were struggling students in maths, who were often saying, "I just can't do it", "You know, it's too hard I can't do it". So with the teaching and with a growth mindset of 'I can't do it yet' she has found great power in using the word 'yet' with the kids. So they can't do it yet but if they persevere and you know, stick with the task and stick with her, that they will actually get there. Sarah, PLT leader

Another element of a growth mindset is the willingness to 'have a go', and make mistakes; and viewing this as an integral aspect of learning. The fact that G.R.I.N. involves students exploring mathematical ideas in a relatively intimate setting characterized by mutual trust may have been responsible for students being willing to attempt mathematical problems they were unsure of, even when back in their mathematics classroom. As Chris, a Leading Teacher (Mathematics), explained:

The biggest benefits for students, I think, are confidence, particularly confidence in going into solving problems. So being able to have a problem that they didn't know the answer to and be able to have the confidence to make some mistakes and try some different things within solving it. I think that's been the biggest change, as opposed to 'I can't do it and shut down and I'm not going to do anymore' or 'I can't do it so I'm going to look for an excuse to get out of the classroom and do something, misbehave or whatever'. Chris, Leading Teacher (Mathematics)

However, Chris also noted that it was sometimes difficult for students to sustain their growth mindset once the material became more challenging. This is a useful reminder that a program such as G.R.I.N. is unlikely to be a panacea, and that changing the way one thinks about themselves as a learner can be a slow and difficult process:

In the first 4-6 weeks, (some students were) really high confidence and they were loving it and then they were coming back to class and they were doing really well so the expectations went up on what they could do and the amount of work they could do... But as it started getting harder... about the 8 week mark, they were sometimes starting to say, "I don't want to do this anymore. This is too hard". There would be a few weeks where we had to really push them to actually go to the G.R.I.N. sessions and we were saying, "No you can't just give up now that it's getting hard". It sort of got to that point when they grew a lot quickly and then the growth slowed down a bit for them. So, getting kids through that bit was a challenge. Chris, Leading Teacher (Mathematics)

\section{Engagement}

Another significant benefit to participating in the G.R.I.N. program was its impact on student enthusiasm and engagement in mathematics class. In particular, students seemed more willing to contribute to discussion and more actively participated in their lessons. As Chris states:

A noticeable change in confidence, participation in class activities, much more engaged in discussions, mathematical discussions and reflections in the classroom. They were the biggest ones. We did see a spark in their data over time [pre and post test data] but the biggest one was confidence level in the classroom. Chris, Leading Teacher (Mathematics)

Peta, one of the G.R.I.N. tutors interviewed, who was also the school's numeracy leader, concurred. She noted that increased self-efficacy in mathematics as a direct result of participating in G.R.I.N. appeared to be translating to greater engagement with mathematical discussion back in the classroom:

\footnotetext{
We have noticed more so a change in their confidence. They are putting their hands up more in class. They're coming to G.R.I.N. knowing now that this will help them in their classroom maths session and they are coming back the following day with "oh, this helped me in my class yesterday or I am now the smart kid in class" because they can see a difference it's really impacted their confidence. We only do it twice a week considering and it's a pretty profound impact. Peta, G.R.I.N. Tutor and Numeracy Leader
}

The other G.R.I.N. tutor interviewed, Alicia, also a Literacy and Numeracy Intervention teacher, noted how student levels of engagement and enthusiasm for participating in the G.R.I.N. program itself changed considerably over the course of the program. To some extent, this reflected students having a better understanding of the purpose of G.R.I.N. (an issue discussed in the next section): 
I suppose their enthusiasm for maths, in terms of at the start they didn't even want to come to G.R.I.N., they really just didn't want to do maths. They used to say to me we are just getting punished, this is like a punishment, we are no good, we suck. Then as time went on, I was getting, are we having G.R.I.N. today? Are you going to be here? Are we having G.R.I.N. tomorrow?... And then when I have to discontinue some of them because they caught up, I still want to come to G.R.I.N. though? Can I still come?... So that kind of shift more than anything that I noticed. Alicia, G.R.I.N. Tutor and Literacy and Numeracy Intervention Teacher

Alicia suggested that participating in the G.R.I.N. program provided opportunities for students to actively ask questions and engage in mathematical dialogue, due to the small group setting:

The kids have loved the G.R.I.N. program saying "It's so easy to understand". Because there are only 3-4 students the kids get a chance to ask their questions. Alicia, G.R.I.N. Tutor and Literacy and Numeracy Intervention Teacher

Consequently, it may be speculated that the G.R.I.N. program enhanced student engagement with mathematical discussion back in the classroom through two mechanisms. First, it familiarized students with the material to be learnt, and the relevant mathematical language, allowing students to make better sense of the content being explored in whole-class mathematical discussions, and thus be more inclined to participate. Secondly, it familiarized students with the process of being engaged in a mathematical discussion; an experience that may have been previously largely unavailable to them. Having this experience on a smallscale (i.e., in their G.R.I.N. group) would likely give students the confidence to engage with such a discussion on a larger-scale (i.e., in a whole-class context).

\section{Systemic Challenges: Communication and Coordination}

\section{Understanding the purpose of G.R.I.N.}

Insights and perspectives from the teachers and tutors interviewed for the current study suggested that, at the beginning of the program, many of the potential stakeholders did not have a clear understanding of the purpose of G.R.I.N.. Specifically, there was evidence that, at least in some instances, classroom teachers, G.R.I.N. tutors, and students themselves were uncertain about either how the program worked and/or whom the program was targeting.

Sarah highlighted how significant staff turnover in their secondary mathematics team had led to some uncertainty about what G.R.I.N. was, which had implications for how these classroom teachers worked with the G.R.I.N. tutors:

We have had a number of staff changes in our secondary maths. So...It's a little haphazard; I think [laughs] this might be the best way to describe our secondary maths team at the moment...but I am expecting that next year as we sort of head down the track the key teachers who will be in the maths team are aware of what G.R.I.N. is, they know what the tutor can do, and they will be working more closely with the G.R.I.N. tutor than has happened sometimes this year. Sarah, PLT leader

This issue of classroom teachers not having a clear sense of the purpose of G.R.I.N., nor being particularly interested in the program, was also highlighted by Alicia:

They kind of see it at a separate thing... They could see there was a change in the kids, but then it was kind of like well that is just the separate program you do. It doesn't really have anything to do with my classroom. Alicia, G.R.I.N. Tutor and Literacy and Numeracy Intervention Teacher

Conversely, Chris noted that, in his school, it was the G.R.I.N. tutor who in fact seemed to misunderstand her role, at least initially. Despite attending the program's professional learning, the G.R.I.N. tutor approached the G.R.I.N. sessions as if she was responsible for teaching all of the mathematical content to students, rather than front-loading students for their regular mathematics class.

With our main G.R.I.N. tutor, so she was not a teacher, so she was an integration aid but very capable in mathematics. She had a background in physics and IT but training her up to... She was sort of trying to teach the entire maths lesson in 20 minutes or half an hour rather than...It took a lot of work to get her into the mindset, even though she did the G.R.I.N. course as well... to get her in the mindset that this was a front loading session, it's not replacing a maths session. Chris, Leading Teacher (Mathematics) 
Perhaps more problematically, there was also evidence, at least in one school, that students misunderstood the purpose of G.R.I.N., viewing it as a remedial program, rather than as an opportunity to enhance their learning. As Sarah put it:

We probably were too guilty at the beginning of introducing G.R.I.N., of jumping in too fast... we didn't promote what the program was all about to the kids. So we struggled in the first term because the kids didn't understand what it was [on] about. They thought they were coming out because they were the 'dummies' and those sorts of things. Sarah, PLT leader

Encouragingly, as the year progressed, attitudes towards G.R.I.N. improved amongst the students, which seemed at least partly a consequence of leadership being more directly involved in explaining the program to targeted students:
So we rectified that... We got the Maths teachers and the Maths coach and in some instances we got the Assistant Principal to explain what the program was about. To explain that they weren't the 'dummies' and that they were just struggling with some bits of Maths and this was going to help them catch up... Sarah, PLT leader

The importance of ensuring that students have a clear sense of the purpose and potential benefits of G.R.I.N. is vital, given the power of students' social networks to affect the sustainability of the program. As Sarah concluded:

(Students) who have applied themselves to G.R.I.N. are now starting to say, "It made a difference for me". The word of mouth from the students here is worth like a pot of gold. Sarah, PLT leader

\section{Timetabling}

All four of the participants highlighted how timetabling G.R.I.N. sessions remained a challenging aspect of implementing the program. Chris succinctly summarized this issue when he stated:

Honestly, the usual timetabling challenges were really hard. Chris, Leading Teacher (Mathematics)

Sarah noted the importance of support from leadership and the school's administration in prioritizing G.R.I.N. sessions:

Timetabling is always an issue. Finding the time in a busy secondary program where kids are prepared to come out (without kicking up a fuss), to come out three times a week and miss out on perhaps other subjects that they like doing has always been challenging for us. We have played around with that and tried to sort of find ways around it. We have a very supportive administration team here who sort of say, "well no, bad luck, you've got to go" and that has helped us. Sarah, PLT leader

It should be noted that this issue was not limited to secondary schools, where it might be assumed that schools have less flexibility over timetabling, compared with a generalist primary setting. Both tutors who operated G.R.I.N. in primary school settings noted that working with students in the upper primary years offers singular timetabling challenges:

\section{It has been challenging in the 5-6 area because there are lots of other demands. As in at the moment they are doing health healthy relationships so that's impacting on timetables and when I can take kids. So, the kids can only come when they are free and they are doing graduation so that's going to impact. There is lots of interruptions. Alicia, G.R.I.N. Tutor and Literacy and Numeracy Intervention Teacher}

Timetabling would be our biggest issue and we are conscious that we don't want to take children who need support in literacy out as well as for numeracy. Peta, G.R.I.N. Tutor and Numeracy Leader

\section{Planning}

Communication between the G.R.I.N. tutor and the classroom teacher was flagged as another challenging aspect of the program, particularly in relation to the classroom teacher sharing their lesson plans in advance. Indeed, Alicia noted that receiving the team's planners in a timely manner was an impediment to them appropriately planning G.R.I.N. sessions. 
My biggest issue is that getting the teachers to see that they do need to plan ahead of time so that I know what I need to preload the kids with. Because I'd turn up on a Monday and there would be nothing planned or it would be put on late Sunday night. I need more time because I would take them first thing Monday morning. Alicia, G.R.I.N. Tutor and Literacy and Numeracy Intervention Teacher

Chris indicated that the ideal scenario would be to have the G.R.I.N. tutor involved in planning sessions:

I think one of the biggest challenges is communication between the teachers and the tutors...so it was more having our teachers all planning together and being on the same page as to what they are teaching and where they are going... if possible having the G.R.I.N. tutor working more and being in all of those planning sessions and things with the team. Chris, Leading Teacher (Mathematics)

\section{Target group}

All interviewees seemed to have a clear idea of who the G.R.I.N. program is intended to target. It was noted that the program is not designed to benefit students who have significant learning difficulties in mathematics, but rather those students who could conceivably catch up with their peers through a year of intensive support. As Sarah stated:

\section{G.R.I.N. is helping us to lift our cohort of students who are 6 months behind so they are clearly moving. Sarah, PLT leader}

However, one of the challenges, particularly for a smaller school, is having a sufficient number of students that are in scope for participation in G.R.I.N.. Alicia indicated that finding students that fit the G.R.I.N. criteria was not possible in her school context, and as a consequence, she had to select some students for participation who were far further behind their peers:

The other challenge I had, was when I looked at our data, we had kids that were at or above or way behind, we didn't really have kids who were 6-8 months behind. So, I had to go to my nearest cohort which was probably a year and a half behind. Alicia, G.R.I.N. Tutor and Literacy and Numeracy Intervention Teacher

Such realities around which of the students participating in G.R.I.N. at a given school actually meet the criteria has clear implications for how much growth it is realistic to expect such students to make in a year.

\section{Contested Areas: Pedagogy and Professional Expertise}

\section{Implications for how mathematics should be taught and Who is the expert?}

Our last two categories arising from our analysis of the interview data will be discussed together as they are inextricably connected. One of the contested issues arising from the analysis of the teacher and tutor interviews was the impact of participating in G.R.I.N. on pedagogy. Chris indicated that undertaking the G.R.I.N. professional learning positively impacted his confidence as a mathematics teacher and leader:

It's given me some more confidence in my teaching and given me more confidence in my leadership and coaching role in the school... it has given me a few more tools and a few more ideas and another bunch of research to support where I am going and for those teachers to use and grab onto. Chris, Leading Teacher (Mathematics)

For Chris, the largest impact on his own practice might have been a move further away from focusing on procedural learning and instead a more explicit focus on problem-solving.

It has confirmed for me the path of using lots of rich task within teaching mathematics so focussing on teaching mathematical concepts as opposed to procedures. I was doing that already but it really solidified for me the importance of it. Chris, Leading Teacher (Mathematics)

However, there are other examples where G.R.I.N. tutors and teachers explicitly stated that they do not believe that participating in G.R.I.N. has changed their personal practice, nor the the way mathematics is taught in their school in general. 
My teaching of maths hasn't probably changed as much as others as I was already a numeracy coach. So, I was probably already doing a lot of the things that we covered in the PD. Alicia, G.R.I.N. Tutor and Literacy and Numeracy Intervention Teacher

I wouldn't say there has been a change in teaching, no. Peta, G.R.I.N. Tutor and Numeracy Leader

Indeed, despite describing how participating in the G.R.I.N. professional learning has helped to refine his own practice, Chris concurred that G.R.I.N. did not appear to have impacted on the way mathematics was taught at his school more generally. More problematically, he noted there appeared to be a disconnect between the pedagogies being pursued in G.R.I.N., and the pedagogies used in many of the classrooms at his school.

Some of our teachers think in the mindset of, they go off to G.R.I.N. and they do that and that sort of operates separately. So really getting the mathematical approaches that happen in G.R.I.N. being implemented in the classroom generally as well...so the same sorts of open-ended problem solving, conceptual based activities. Chris, Leading Teacher (Mathematics)

In general, the G.R.I.N. professional learning emphasized student-centered activities based on reformoriented approaches to instruction. If regular classroom mathematics lessons were instead built around more traditional, teacher-centered, instructional approaches, the impact of G.R.I.N. on overall student learning might be limited.

In a similar manner to Chris, Alicia also noted such a pedagogical disconnect in her school. From her perspective, she was already using what she implied were student-centered pedagogical approaches, and participating in G.R.I.N. and becoming a G.R.I.N. tutor was simply allowing her to implement what she already viewed as good practice. This was clearly a significant source of frustration for Alicia, particularly in relation to classroom teachers attitudes towards manipulatives:

I was trying to model with the kids how to use equipment, how to use materials, oh you can use them in your maths class today and then they would come back as say oh our teacher wouldn't let us and I would say maybe you need to take it in and show it to your teacher. I was trying to get an inroad that way. Yes, very frustrating, especially when the kids are asking "why can't we use this in maths?" and I was saying "well you need to show your teacher that you want to use it". I was dealing with 5-6's and I believe that they should be always using materials. So, my room has probably got more materials than their classroom. And I was pulling out the MAB and pulling out money and Cuisenaire. You can only do so much. Alicia, G.R.I.N. Tutor and Literacy and Numeracy Intervention Teacher

For Tracey, the assumption inherent in the G.R.I.N. model that the tutor should follow the sequence of learning designed by the classroom teacher was problematic because she clearly believed she had significantly more expertise in mathematics instruction than the classroom teachers planning the unit.

I have no input into the planning. I can view their planning but I have no input into their planning. So, there is no opportunity for me to impact on that planning. I would like to be able to say "this is what I found, maybe we need to do this in the next lesson". So pretty much I have to follow their planning even though I often think this is not the sequence I would do. Alicia, G.R.I.N. Tutor and Literacy and Numeracy Intervention Teacher

This issue identified by Alicia may be a particular challenge in primary schools contexts, where G.R.I.N. tutors might be leading teachers, numeracy coordinators or specialists, whose responsibility is to prepare students for a sequence of lessons being implemented by a generalist classroom teacher. Such a scenario is likely to lead to the potentially problematic situation whereby the G.R.I.N. tutor has significantly greater mathematical pedagogical content knowledge than the classroom teacher. In such instances, it would seem highly advisable that the G.R.I.N. tutor be involved in planning the lesson sequences (when feasible); a position also put forward by Chris in his secondary school context (as highlighted under the discussion of the category Planning).

\section{DISCUSSION AND CONCLUDING REMARKS}

Our first research question focused on G.R.I.N. tutors and classroom teachers' perceptions of the student experience of participating in the G.R.I.N. initiative. The interview data suggests that the G.R.I.N. intervention program has been successful in re-engaging underperforming students in mathematics learning. 
Specifically, there is evidence that G.R.I.N. students showed improved cognitive, behavioural and affective engagement (Fielding-Wells \& Makar, 2008). For example, tutors and teachers noted that participating in G.R.I.N. sessions appeared to activate the prior mathematical knowledge of students, leading to cognitive engagement in subsequent mathematics session. The G.R.I.N. students' willingness to be more active participants in their mathematics lessons by both posing and answering questions during whole-class discussion was also indicative of both behavioural and affective engagement. In addition to enhanced engagement, it is also important to focus our attention on what factors appeared to support G.R.I.N. students to develop and maintain a growth mindset, and adopt a mastery goal orientation (Dweck, 2000, 2008).

G.R.I.N. sessions comprise of a G.R.I.N. tutor and three underperforming and (dis)engaged students in mathematics. Teachers and tutors reported that this structure allowed students to work closely with the G.R.I.N. tutor in a less intimidating environment when compared to a typical, larger group classroom. Tutors in particular noted that the G.R.I.N. students are provided with more opportunities in the G.R.I.N. session to ask questions and resolve misunderstandings. It appears that the increased familiarity of mathematics content and associated processes reduced the risk of failure for students, in turn encouraging them to contribute to classroom discussions and attempt the completion of set tasks. In essence, there was in fact evidence that participating in the program supported students to believe that, through effort, they could succeed with their mathematics learning (Dweck, 2000).

Our second research question focused on some of the perceived challenges to implementing the G.R.I.N. initiative in a school. Some of the identified challenges were logistical, such as being able to appropriately timetable the G.R.I.N. sessions, timely planning of lesson materials and collaborative planning opportunities between the G.R.I.N. tutor and classroom teachers, and having enough students in the G.R.I.N. target group as potential participants. Other challenges related to communication about the purpose of G.R.I.N. to stakeholders, including classroom teachers, potential G.R.I.N. tutors and students. All of these challenges reinforce the notion that for the G.R.I.N. program to be effective, a whole-school approach with strong leadership support are important pre-requisites.

A further challenge to implementing G.R.I.N. relates to tension between tutors and teachers as to how mathematics should be taught, and who is the expert. Clearly both tutors and teachers are likely to offer important perspectives about a particular student's learning, and both may have value contributions to make regarding the sorts of pedagogies most likely to support these students. Although this issue is complex to navigate, particularly when the G.R.I.N. tutor has a dual role as an expert teacher, it is anticipated that putting in place processes to support regular and open communication between educators, such as opportunities for the tutor to participate in team planning, can help reduce such tensions.

Such collaborative planning opportunities are likely to have important auxiliary benefits beyond reducing the tension between educators. As discussed previously, the quality and frequency of communication between the tutor and the classroom teacher is critical to the success of the program and adequate time must be factored into the school timetable for this to occur. Due to the varying experiences in teaching between the G.R.I.N. tutor and the classroom teacher, perhaps the establishment of a professional learning team (PLT) that meets regularly to share thoughts, opinions and ideas on good teaching practices and student progress could help to capitalize on skills and provide ongoing professional development. For example, the skills, understandings and misconceptions observed by the tutor during the G.R.I.N. sessions are likely to exist to some degree in other 'non- G.R.I.N.' students within the classroom. The tutor's input can therefore provide invaluable insight for the classroom teacher about their students' understandings in mathematics more generally. The G.R.I.N. tutor is in a position to make suggestions about teaching strategies to support those experiencing difficulties. This has the potential to improve the flow of the classroom lesson and make the classroom learning experience generally more effective for all students. This discussion again highlights the importance of leadership for ensuring that the G.R.I.N. program has a maximum positive impact on the student learning experience, through factors such as providing structural supports for the program (e.g., establishing PLTs).

Better understanding how tensions in the (pedagogical) values between teachers and tutors manifest, evolve and (perhaps) resolve, and the mechanisms that support their resolution, appears to be an important direction for future research. However, equally as important is to gain further insight into how G.R.I.N. can support the purposeful shaping of students' valuing, particularly given that this would seem to have important implications for sustaining a growth mindset. Future research should directly examine the interactions between teachers, tutors and students, in order to bring to fore what these stakeholders value similarly and differently and how these value differences are negotiated. 


\section{Disclosure statement}

No potential conflict of interest was reported by the authors.

\section{Notes on contributors}

Penelope Kalogeropoulos - Monash University, Australia.

James A Russo - Monash University, Australia.

Peter Sullivan - Monash University, Australia.

Michele Klooger - Monash University, Australia.

Sue Gunningham - Monash University, Australia.

\section{REFERENCES}

Alzahrani, K. S. (2017). Metacognition and Cooperative Learning in the Mathematics Classroom. International Electronic Journal of Mathematics Education, 12(3), 475-491.

Bransford, J. B., Brown, A. L., \& Cocking, R. R. (Eds.) (1999). How people learn: Brain, mind, experience, and school. London: Committee on Developments in the Science of Learning, National Research Council.

Clarke, B., Doabler, C. T., Kosty, D., Kurtz Nelson, E., Smolkowski, K., Fien, H., \& Turtura, J. (2017). Testing the efficacy of a kindergarten mathematics intervention by small group size. AERA open, 3(2), 2332858417706899. https://doi.org/10.1177/2332858417706899

Davadas, S. D., Lay, Y. F. (2018). Factors Affecting Students' Attitude toward Mathematics: A Structural Equation Modeling Approach. Eurasia Journal of Mathematics, Science and Technology Education, 14(1), 517-529. https://doi.org/10.12973/ejmste/80356

Desforges, C., \& Cockburn, A. (1987). Understanding the mathematics teacher: A study of practice in first schools. London, UK: Taylor \& Francis.

DiNapoli, J. (2019). Persevering toward What? Investigating the Relationship between Ninth-grade Students' Achievement Goals and Perseverant Actions on an Algebraic Task. International Electronic Journal of Mathematics Education, 14(3), 435-453. https://doi.org/10.29333/iejme/5747

Dweck, C. S. (2000). Self theories: Their role in motivation, personality, and development. Philadelphia, VA: Psychology Press.

Dweck, C. S. (2008). Mindset: The new psychology of success. New York, NY: Random House Digital, Inc.

Elliot, A. J. (1999). Approach and avoidance motivation and achievement goals. Educational Psychologist, 34 (3), 169-189. https://doi.org/10.1207/s15326985ep3403_3

Fielding-Wells, J., \& Makar, K. (2008). Student (dis)engagement in mathematics. Paper presented at the Annual Conference of the Australian Association for Research in Education, Brisbane, Australia. http://www.aare.edu.au/08pap/mak08723.pdf

Fredricks, J. A., Blumenfeld, P. C., \& Paris, A. H. (2004). School engagement: Potential of the concept, state of the evidence. Review of educational research, $74(1), \quad 59-109$. https://doi.org/10.3102/00346543074001059

Foorman, B. R., Francis, D. J., Winikates, D., Mehta. P., Schatschneider, C, \& Fletcher. J. M. (1997). Early interventions for children with reading disabilities. Scientific Studies of Reading, 1(3), 255-276. https://doi.org/10.1207/s1532799xssr0103_5

Glaser, B. G. (1965). The constant comparative method of qualitative analysis. Social problems, 12(4), 436445. https://doi.org/10.2307/798843

Gottfried, M. A. (2019). Chronic absenteeism in the classroom context: Effects on achievement. Urban Education, 54(1), 3-34.

Graham, L., Bellert, A., Thomas, J., \& Pegg, J. (2007). QuickSmart: A basic academic skills intervention for middle school students with learning difficulties. Journal of Learning Disabilities, 40(5), 410-419. https://doi.org/10.1177/00222194070400050401

Hannula, M. (2004). Affect in mathematical thinking and learning. Turku: Turun Yliopisto.

Hattie, J. (2009). Visible learning: a synthesis of meta-analysis relating to achievement. Falmer: Routledge. 
Huang, Y.-H. (2018). Influence of Instructional Design to Manage Intrinsic Cognitive Load on Learning Effectiveness. Eurasia Journal of Mathematics, Science and Technology Education, 14(6), 2653-2668. https://doi:10.29333/ejmste/90264

Kieran, C. (2001). The mathematical discourse of 13-year-old partnered problem solving and its relation to the mathematics that emerges. Educational Studies in Mathematics, 46(1-3), 187-228. https://oi.org/10.1023/a:1014040725558

Kong, Q.-P., Wong, N.-Y., \& Lam, C.-C. (2003). Student engagement in mathematics: Development of instrument and validation of construct. Mathematics Education Research Journal, 15(1), 4-21. https://doi.org/10.1007/bf03217366

Martin, A. J., \& Marsh, H. W. (2006). Academic resilience and its psychological and educational correlates: A construct validity approach. Psychology in the Schools, 43(3), 267-281. https://doi.org/10.1002/pits.20149

Pijls, M., Dekker, R., \& Van Hout-Wolters, B. (2007). Reconstruction of a collaborative mathematical learning process. Educational Studies in Mathematics, 65(3), 309-329. https://doi.org/10.1007/s10649-006-90513

Pollock, E., Chandler, P., \& Sweller, J. (2002). Assimilating complex information. Learning and instruction, 12(1), 61-86. https://doi.org/10.1016/s0959-4752(01)00016-0

Russo, J., \& Hopkins, S. (2017). Student reflections on learning with challenging tasks: 'I think the worksheets were just for practice, and the challenges were for maths'. Mathematics Education Research Journal, 29(3), 283-311. https://oi.org/10.1007/s13394-017-0197-3

Strauss, A., \& Corbin, J. (1994). Grounded theory methodology. Handbook of qualitative research, 17, 273-85.

Sullivan, P., \& Gunningham, S. (2011). A strategy for supporting students who have fallen behind in the learning of mathematics. In J. Clarke, B. Kissane, J. Mousley, T. Spencer, \& S. Thornton (Eds.), Mathematics: Tradition and [New] Practices. Proceedings of the 34th Annual Conference of the Mathematics Education Research Group of Australasia and the Australian Association of Mathematics Teachers (pp. 719-727). Adelaide: AAMT and MERGA.

Sullivan, P., \& McDonough, A. (2007). Eliciting positive student motivation for learning mathematics. In J Watson, J. \& K Beswick (Eds.), Mathematics: Essential Research, Essential Practice: Proceedings of the 30th Annual Conference of the Mathematics Education Research Group of Australasia (pp. 698-707). Hobart: MERGA.

Sullivan, P., Mousley, J., \& Zevenbergen, R. (2006). Developing guidelines for teachers helping students experiencing difficulty in learning mathematics. In P. Grootenboer, R. Zevenbergen \& M. Chinnappan (Eds.), Identities, cultures and learning space: Proceedings of the 29th annual conference of the Mathematics Education Research Group of Australasia (pp. 496-503). Sydney: MERGA.

Sweller, J. (2010). Element interactivity and intrinsic, extraneous, and germane cognitive load. Educational psychology review, 22(2), 123-138. https://doi.org/10.1007/s10648-010-9128-5

Thomson, S., Wernert, N., O'Grady, E., \& Rodrigues, S. (2016). TIMSS 2015: A first look at Australia's results. ACER: Camberwell.

Van Merrienboer, J. J., \& Sweller, J. (2005). Cognitive load theory and complex learning: Recent developments and future directions. Educational psychology review, 17(2), 147-177. https://doi.org/10.1007/s10648005-3951-0

Vaughn, S., Cirino, P. T., Wanzek, J., Wexler, J., Fletcher, J. M., Denton, C. D., . . Francis, D. J. (2010). Response to intervention for middle school students with reading difficulties: Effects of a primary and secondary intervention. School Psychology Review, 39(1), 3-21.

Vaughn, S., Linan-Thompson, S., Kouzekanani, K., Pedrotty Bryant, D., Dickson, S., \& Blozis, S. A. (2003). Reading instruction grouping for students with reading difficulties. Remedial and Special Education, 24(5), 301-315. https://doi.org/10.1177/07419325030240050501

Wanzek, J., \& Vaughn, S. (2007). Research-based implications from extensive early reading interventions. School Psychology Review, 36(4), 541-562. 
Yoon, J., Thye, S. R., \& Lawler, E. J. (2013). Exchange and cohesion in dyads and triads: A test of Simmel's hypothesis. Social science research, 42(6), 1457-1466. https://doi.org/10.1016/j.ssresearch.2013.06.003

Zakaria, E., Chin, L. C., \& Daud, M. Y. (2010). The effects of cooperative learning on students' mathematics achievement and attitude towards mathematics. Journal of social sciences, 6(2), 272-275. https://doi.org/10.3844/jssp.2010.272.275

http://www.iejme.com 